\title{
O enigma da existência: defesa da abordagem rejeicionista
}

\author{
Luís Carlos Vicente Ramos \\ UNIVERSIDADE DO PORTO
}

\begin{abstract}
RESUMO
Neste artigo defenderei, contra Nicholas Rescher, a abordagem rejeicionista como solução para o enigma da existência. Com esse objetivo em vista, o artigo divide-se em duas partes: na primeira, defenderei a viabilidade dessa abordagem; na segunda, proporei um novo argumento a favor dessa abordagem.

Palavras-chave: existência; nada; princípio da unidade essencial dos contrários; abordagem rejeicionista; algo.
\end{abstract}

\begin{abstract}
In this paper I will defend, against Nicholas Rescher, the rejectionist approach as a solution to the riddle of existence. With this objective in mind, the article is divided into two parts: in the first, I will defend the feasibility of this approach; in the second, I will propose a new argument in favor of this approach.

Keywords: existence; nothing; principle of essential unity of opposites; rejectionist approach; something.
\end{abstract}

\section{Introdução}

Nicolas Rescher, ao tentar solucionar o chamado enigma da existência, o qual formula através da questão 'porque existe algo em vez de nada?' (Rescher 1999:7), antes de chegar àquela que considera ser a solução mais plausível para esse enigma, nomeadamente, 
a abordagem nomológica, apresenta várias respostas para esta questão, que vai descartando ao longo da discussão.

Uma dessas respostas, e contra a qual Rescher argumenta, é a abordagem rejeicionista. Segundo escreve o filósofo, os proponentes desta abordagem defendem que 'a questão deve ser abandonada como imprópria - por não representar uma questão legítima', uma vez que "à luz de um exame mais minucioso, o "problema" explicativo', isto é, o problema de explicar porque existe algo em vez de nada, 'desaparece como sem sentido' (Rescher 1999:14).

Posto isto, o principal objetivo deste artigo é defender, contra Rescher, a abordagem rejeicionista como solução para este enigma.

Com esse objetivo em vista, dividirei este artigo em dois capítulos.

No primeiro capítulo, a fim de defender, contra Rescher, que a abordagem rejeicionista é viável para responder à questão de existir algo em vez de nada, vou dar três passos: o primeiro passo será apresentar o argumento de C. G. Hempel, que Rescher considera ser o principal argumento para defender esta abordagem; o segundo passo será apresentar o contra-argumento de Rescher a esse argumento; $\mathrm{e}$ o terceiro passo será apresentar uma crítica a esse contra-argumento de Rescher no sentido de defender o argumento de Hempel.

No segundo capítulo, a fim de propor um novo argumento para essa abordagem, depois de no primeiro capítulo ter defendido a viabilidade da mesma, vou dar também três passos: o primeiro passo será explicar porque considero ser necessário apresentar um novo argumento; o segundo passo será defender as três premissas que constituirão o argumento; e o terceiro passo será apresentar o argumento.

\section{Defesa da viabilidade da abordagem rejeicionista contra Rescher}

\subsection{O argumento de C. G. Hempel}

O primeiro passo que vou tomar a fim de defender a viabilidade da abordagem rejeicionista contra Rescher será apresentar aquele que 
ele considera ser o principal argumento a favor de tal abordagem (Rescher 1999:14), nomeadamente, o argumento de Hempel que se segue (Hempel 1973:200).

Primeira fase do argumento:

PREMISSA 1: Toda a resposta explicativa do tipo $A e ́$ explicado por $B$ é logicamente possível se e somente se for o caso que, para explicar A, B corresponde à existência de algo.

PREMISSA 2: Toda a resposta adequada para a questão porque existe algo em vez de nada? é uma resposta explicativa tal que, para explicar A, B não pode corresponder à existência de algo.

CONCLUSÃo 1: Logo, toda a resposta adequada para a questão porque existe algo em vez de nada? não é logicamente possível.

Segunda fase do argumento:

[PREMISSA 3: Toda a questão construída de forma que uma resposta adequada não é logicamente possível deve ser rejeitada.] CONCLUSÃo 1: Toda a resposta adequada para a questão porque existe algo em vez de nada? não é logicamente possível. CONCLUSÃO 2: Logo, a questão porque existe algo em vez de nada? deve ser rejeitada.

\subsection{O contra-argumento de Rescher}

O segundo passo que vou tomar a fim de defender a viabilidade da abordagem rejeicionista contra Rescher será apresentar o seu contra-argumento (Rescher 1999:15). 
PREMISSA 1: O argumento de Hempel é um bom argumento para defender a abordagem rejeicionista se e somente se a 'tese da homogeneidade genética' é verdadeira. Esta tese, que se sustenta no 'princípio grego antigo de que 'o mesmo deve vir do mesmo' e cujo nome deriva da 'analogia com o antigo, mas agora bastante obsoleto princípio de que "a vida deve vir da vida"', defende a ideia de que existe 'uma homogeneidade de tipo entre causa e efeito'. (Rescher 1999:15). Isto é, B, para explicar o algo $\mathrm{A}$, tem de ter uma constituição idêntica à de $\mathrm{A}$, ou seja, tem de ser um algo $B$.

PREMISSA 2: Várias evidências científicas, tais como, por exemplo, o facto de que, tal como nota Rescher, 'a matéria pode vir da energia' (Rescher 1999:15) provam que a tese da homogeneidade genética não é verdadeira.

CONCLUSÃo: Logo, o argumento de Hempel não é um bom argumento para defender a abordagem rejeicionista.

\subsection{Crítica ao contra-argumento de Rescher}

O terceiro passo que vou tomar a fim de defender a viabilidade da abordagem rejeicionista contra Rescher será apresentar a minha crítica a este contra-argumento que ele elabora contra Hempel.

Para esse efeito, gostaria de me centrar na segunda premissa do mesmo. Aí, o filósofo critica a tese da homogeneidade genética através de exemplos em que $\mathrm{B}$ e $\mathrm{A}$, para o primeiro explicar o segundo, não necessitam de ter uma constituição idêntica - tal como é o caso da matéria, que, sendo constitutivamente diferente da energia, pode provir dela.

Porém, se analisarmos o exemplo de Rescher com atenção, percebemos que esse não é um exemplo em que a tese da homogeneidade genética não se aplique, pois, apesar de a matéria e a energia 
parecerem constitutivamente diferentes, quando analisadas ao nível mais geral possível que é pedido pela questão porque existe algo em vez de nada? - verifica-se que elas são, a esse nível, constitutivamente idênticas, na medida em que, quer a matéria, quer a energia, são algo'.

Logo, concluo que o exemplo de Rescher, em última análise, ao contrário daquilo que ele pretendia, é mais uma razão para sustentar a tese da homogeneidade genética, o que, colocando em causa a segunda premissa, nos permite recusar o seu contra-argumento - pelo que a abordagem rejeicionista, assente no argumento de Hempel, parece continuar a ser viável para responder à questão porque existe algo em vez de nada?

\section{Proposta de um novo argumento para defender a abordagem rejeicionista}

\subsection{Porque considero ser necessário apresentar um novo argumento?}

O primeiro passo que vou tomar a fim de propor um novo argumento para defender a abordagem rejeicionista será explicar por que razão considero ser necessário apresentar um novo argumento. A razão é a seguinte:

Embora julgue, como defendi, que a abordagem rejeicionista é viável para responder à questão porque existe algo em vez de nada?, penso que o argumento de Hempel é demasiado fraco para defender competentemente essa abordagem. E essa fraqueza, parece-me, provém do facto de o argumento se apoiar no pressuposto de que toda a resposta adequada para essa questão é uma resposta explicativa do tipo Aé explicado por $B$ e que, demonstrando como não é logi-

\footnotetext{
1 Embora hoje se saiba, considerando as teorias físicas atuais posteriores a Einstein e ao contrário do que parece supor Nicholas Rescher, que matéria e energia são o mesmo, para a minha argumentação, que se situa ao nível dos conceitos algo e nada, basta-me mostrar que ambas são o mesmo simplesmente porque, como defendo, ambas são algo.
} 
camente possível dar uma resposta explicativa do tipo $A$ é explicado por $B$ para a questão porque existe algo em vez de nada?, a mesma deve ser rejeitada. Esse pressuposto enfraquece a defesa da abordagem rejeicionista, na medida em que demonstrar que a adoção arbitrária de um certo tipo de resposta $\mathrm{Y}$ para uma pergunta $\mathrm{Z}$ conduz a que seja impossível responder-lhe não invalida quer a hipótese plausível de que existem outros tipos de resposta que são tão adequados para responder à questão quanto a resposta explicativa, quer a hipótese plausível de que esses outros tipos de resposta permitem dar uma resposta logicamente possível para a questão - o que poria em causa esta abordagem rejeicionista.

É, pois, necessário, para continuar a apoiar essa abordagem, apresentar um argumento mais forte do que esse, isto é, um argumento que, indubitavelmente, constitua uma prova segura de que a abordagem rejeicionista é a mais plausível para responder à questão - tarefa que pretendo realizar ao apresentar este novo argumento.

Penso que este novo argumento será mais forte do que o argumento de Hempel, na medida em que não se centra em defender que a adoção arbitrária de um certo tipo de resposta torna logicamente não possível responder à questão, deixando em aberto se isso também acontece com outros tipos de resposta, mas centra-se em defender que desde logo a própria formulação da pergunta não é logicamente possível.

\subsection{Defesa das três premissas}

O segundo passo que vou tomar a fim de propor um novo argumento para defender a abordagem rejeicionista será defender as três premissas que constituirão o argumento.

\subsubsection{Defesa da primeira premissa}

Para defender esta primeira premissa, partirei do pressuposto de que:

Se não é verdade que $P$, então a pergunta porquê $P$ ? não é logicamente possível. $\mathrm{E}$ eu penso que isso se deve ao facto de esta pergunta 
assentar na falsa suposição de que é verdade que P. E essa suposição é falsa, uma vez que não é afirmado, como a pergunta supõe, que é verdade que $\mathrm{P}$, mas, pelo contrário, é afirmado que não é verdade que $\mathrm{P}$.

Por exemplo:

Se não é verdade que o Miguel vive em Espanha, então a pergunta porque vive o Miguel em Espanha? não é logicamente possível. E tal como referido anteriormente, penso que isso se deve ao facto de a pergunta assentar na falsa suposição de que é verdade que o Miguel vive em Espanha. E essa suposição é falsa, uma vez que não é afirmado, como a pergunta supõe, que é verdade que o Miguel vive em Espanha, mas, pelo contrário, é afirmado que não é verdade que o Miguel vive em Espanha.

Aplicando este raciocínio à pergunta porque existe algo em vez de nada?, obtenho, consequentemente, a primeira premissa para o meu argumento de defesa da abordagem rejeicionista: Se não é verdade que existe algo em vez de nada, então a pergunta Porque existe algo em vez de nada? não é logicamente possível.

\subsubsection{Defesa da segunda premissa}

De modo a conduzir o argumento para a conclusão de que: a pergunta porque existe algo em vez de nada? não é logicamente possível (o que corresponde ao consequente da implicação da primeira premissa), esta segunda premissa tem de ser tal que eu consiga provar que não é verdade que existe algo em vez de nada (o que corresponde ao antecedente da implicação da primeira premissa).

Para isso, tenho de colocar a seguinte questão: porque não éverdade que existe algo em vez de nada? A resposta que eu considero mais plausível é a seguinte: porque é verdade que existe algo e existe nada. Nos próximos parágrafos vou demonstrar como cheguei até essa resposta. 
Para começar, eu fundamentei a minha resposta num outro princípio da Grécia antiga, diferente daquele que é mencionado por Rescher, mais especificamente, num princípio proveniente do pensamento filosófico de Heraclito, nomeadamente, na formulação do princípio da 'unidade essencial dos contrários' (Kirk, Raven e Schofield 2010:195) que o mesmo assume no fragmento 202, segundo a qual:

\author{
E como uma mesma coisa, existem em nós a vida e a morte, \\ a vigília e o sono, a juventude e a velhice: pois estas coisas, \\ quando mudam, são aquelas, e aquelas, quando mudam, \\ são estas.
}

(Kirk, Raven e Schofield 2010:195, frag. 202)

Para além deste fragmento, o comentário que lhe é feito por J. S. Kirk, J. E. Raven e M. Schofield ajuda-me a cumprir o meu objetivo quando estes afirmam que, nesse fragmento citado anteriormente, 'diz-se que certos contrários estão essencialmente ligados', isto é, 'são "a mesma coisa"' e são 'interdependentes' (Kirk, Raven e Schofield 2010:195-196). Levando em conta estas ideias:

Primeiro, estou em condições de defender que a relação existente entre algo e nada é tal que ambos - assim como os pares vida-morte, vigília-sono, juventude-velhice - são um par de contrários. E isto é assim porque é possível afirmar que algo e nada são uma mesma coisa, o que é possível fazer na medida em que, retomando a formulação desse princípio, algo, quando muda, é nada, e nada, quando muda, é algo.

Segundo, dizer que eles são uma mesma coisa é dizer que eles estão essencialmente ligados e interdependentes.

Terceiro, assim, do mesmo modo que quente e frio, citando ainda o comentário ao fragmento, 'formam o que poderíamos chamar um contínuo quente-frio, uma entidade única (i.e. a temperatura)' (Kirk, Raven e Schofield 2010:196), penso que também podemos dizer que algo e nada formam o que poderíamos chamar um contínuo algo-nada, uma entidade única (i.e. a existência).

Posto isto, se é verdade que a existência é essa entidade única constituída por esse contínuo algo-nada, e se algo e nada são a mesma coisa, na medida em que estão essencialmente ligados e estão 
interdependentes, ou seja, a existência de algo implica a existência de nada e a existência de nada implica a existência de algo, então é verdade que a existência implica algo e nada, e, por conseguinte, é verdade que existe algo e existe nada.

Logo, uma vez que justifiquei que é verdade que existe algo e existe nada, tenho agora uma razão plausível para considerar que: Não é verdade que existe algo em vez de nada - o que corresponde, como referi, à segunda premissa do meu argumento.

\subsubsection{Defesa da terceira premissa}

Por fim, vou defender a terceira premissa do meu argumento recorrendo à seguinte analogia: do mesmo modo que, na minha apresentação do argumento de Hempel, fui obrigado a considerar, na terceira premissa, que o filósofo supunha que: Toda a questão construída de forma que uma resposta adequada não élogicamente possível deve ser rejeitada - para poder levar o argumento de Hempel a desembocar na abordagem rejeicionista, considero-me agora, pela mesma razão, analogamente autorizado a considerar a suposição de que: Toda a pergunta que não é logicamente possível deve ser rejeitada - suposição a qual corresponderá, igualmente, à terceira premissa do meu argumento.

\subsection{Apresentação do argumento}

O terceiro passo que vou tomar a fim de propor um novo argumento para defender a abordagem rejeicionista será construir esse argumento:

Primeira fase do argumento:

PREMISSA 1: Se não é verdade que existe algo em vez de nada, então a pergunta porque existe algo em vez de nada? não é logicamente possível. 
PREMISSA 2: Não é verdade que existe algo em vez de nada.

CONCLUSÃo1: Logo, a pergunta porque existe algo em vez de nada? não é logicamente possível.

Segunda fase do argumento:

PREMISSA 3: Toda a pergunta que não é logicamente possível deve ser rejeitada. CONCLUSÃo 1: A pergunta porque existe algo em vez de nada? não é logicamente possível. CONCLUSÃo 2: Logo, a pergunta porque existe algo em vez de nada? deve ser rejeitada.

\section{Nota final}

Em suma, concluo, contra Nicholas Rescher, que a solução mais plausível para o enigma da existência, formulado através da questão porque existe algo em vez de nada?, é a abordagem rejeicionista, na medida em que o argumento apresentado demonstra que, uma vez que essa questão não é logicamente possível - ela deve ser rejeitada.

\section{REFERÊNCIAS}

Hempel, Carl G. (1973). 'Science Unlimited'. The Annals of the Japan Association for Philosophy of Science. Vol. 14 (1973), pp. 187-202.

Kirk, G., Raven J. e Schofield, M. (2010). 'Heraclito de Éfeso', in Os filósofos pré-socráticos. Fonseca, C. A. L. (trad.). Lisboa: Fundação Calouste Gulbenkian, pp. 187-221.

Rescher, N. (1999). 'On Explaining Existence. (Real Possibility as the Key to Actuality)', in Hales, S. D. (ed.), Metaphysics: Contemporary Readings. Canada: Wadsworth Publishing Company, pp. 7-25. 